\title{
INFLUÊNCIA DE DIFERENTES CONCENTRAÇÕES DE ETILENO GLICOL NO NÚMERO DE CÉLULAS DA GRANULOSA E MORFOMETRIA DE FOLÍCULOS PRÉ-ANTRAIS INCLUSOS EM TECIDO OVARIANO DE Bos taurus indicus, Linnaeus, 1758
}

\author{
Influence of different concentrations of the glycol in the number of granulosa cells and \\ morphometry of the preantral ovarian follicles of Bos taurus indicus, Linnaeus, 1758
}

\author{
Hélder Silva e Luna ${ }^{1}$, Luciana Alves Lijeron², Rafaela Nelson da Costa ${ }^{3}$
}

\begin{abstract}
RESUMO
A criopreservação de folículos ovarianos pré-antrais pode ajudar na conservação de muitas espécies domésticas e selvagens. Neste trabalho, objetivou-se verificar o efeito do etileno glicol, em diferentes concentrações, na morfometria e número de células da granulosa de folículos pré-antrais inclusos em tecido ovariano bovino. O teste de toxicidade foi realizado com fragmentos ovarianos expostos ao etileno glicol em concentrações de 10, $20 \mathrm{ou} 40 \%$. O tecido foi analisado por técnica histológica clássica. Os folículos primordiais expostos à concentração de $40 \%$ apresentaram redução do diâmetro folicular e ovocitário quando comparados ao grupo controle (sem exposição), $10 \%$ e $20 \%$ ( $\mathrm{P}<0,05)$ e redução do número de células da granulosa quando comparados ao grupo controle $(\mathrm{P}<0,05)$. Com relação aos folículos primários, nenhum efeito foi observado $(\mathrm{P}>0,05)$. Esses resultados sugerem que folículos primários são mais resistentes aos efeitos do etileno glicol quando comparados aos primordiais.
\end{abstract}

Termos para indexação: Folículos pré-antrais, histologia, bovino, crioprotetor.

\begin{abstract}
The cryopreservation of the ovarian preantral follicles could help the conservation of several domestic and wild animal species. The objective of this study was to verify the effect of different concentrations of ethylene glycol on the morphometry and number of granulosa cells of the preantral ovarian follicles. A toxicity test was conducted with strips of ovarian cortex using ethylene glycol $(10,20$ or $40 \%)$. Tissue analysis was done using classical histology techniques. The primordial follicles expose at a concentration of $40 \%$ showed reduction of the follicular diameter and oocyte when compared to the control (non exposing), 10 and $20 \%$ groups $(\mathrm{P}<0.05)$ and reduction in the number of granulosa cells compared to the control group $(\mathrm{P}<0.05)$. Regarding the primary follicles no alteration could be observed $(\mathrm{P}>0.05)$. These results suggest that primary follicles are more resistant to the effect of ethylene glycol when compared to primordial ones.
\end{abstract}

Idex terms: Preantral follicles, histology, bovine, cryoprotectant.

(Recebido em 10 de abril de 2007 e aprovado em 17 de julho de 2009)

\section{INTRODUÇÃO}

A manipulação de tecido ovariano destaca-se atualmente como uma das biotecnologias que apresentam grande potencial para conservação de gametas femininos. O estudo da conservação do tecido ovariano ganhou impulso em função de sua aplicabilidade na medicina humana para recuperação da possibilidade de reprodução, principalmente, em pacientes submetidos a tratamentos de quimioterapia ou radioterapia. Essa tecnologia também é frequentemente utilizada em pacientes com doenças autoimunes e artrites reumatóides (Donnez \& Bassil, 1998; Oktay \& Karlikaya, 2000; Aubard et al., 2001; Oktay, 2001) ou mesmo câncer (Posada et al., 2001).
A criopreservação de tecido ovariano animal mostra-se como uma promissora técnica, a qual pode atingir programas conservacionistas e de melhoramento genético animal. Entretanto, para o sucesso da criopreservação, a escolha correta e o conhecimento dos efeitos das substâncias crioprotetoras são de fundamental importância. É sabido que os crioprotetores apresentam efeitos tóxicos aos sistemas biológicos (Schalkoff et al., 1989; Vincent et al., 1990; Fuku et al., 1995), além de, invariavelmente, causarem choques osmóticos (Agca et al., 2000). Com relação ao tecido ovariano, os crioprotetores mais utilizados para congelamento são o dimetilsulfóxido, o propileno glicol, o glicerol e o etileno glicol (Demirci et al., 2003).

${ }^{1}$ Universidade Federal de Mato Grosso do Sul/UFMS - Departamento de Biociências - Praça Nossa Senhora Imaculada Conceição - 163 - $79200-000$ Aquidauana, MS - hluna@ceua.ufms.br

2Universidade Federal de Mato Grosso do Sul/UFMS - Aquidauana , MS

3Universidade Federal de Mato Grosso do Sul/UFMS - Núcleo Ciências Veterinária - Campo Grande, MS 
$\mathrm{Na}$ busca de melhores metodologias de criopreservação e substâncias crioprotetoras para viabilizar a conservação de folículos pré-antrais, estudos têm sido aplicados em várias espécies, como bovinos (Paynter et al., 1999; Lucci et al., 2004), caprinos (Silva et al., 2000), ovinos (Amorim et al., 2003), gatos (Lima et al., 2006), camundongos (Candy et al., 2000) e humanos (Oktay \& Karlikaya, 2000). Conduziu-se este estudo, com o objetivo de verificar o efeito do etileno glicol, em diferentes concentrações, na morfometria e número de células da granulosa de folículos pré-antrais inclusos em tecido ovariano bovino.

\section{MATERIAL E MÉTODOS}

Ovários de vacas zebus (cinco ovários de diferentes animais) foram coletados aleatoriamente em abatedouro e transportados ao laboratório à temperatura ambiente no intervalo de uma hora. Os ovários foram lavados em álcool $70 \%$ seguido de solução de $\mathrm{NaCl}$ a $0,9 \%$. Pequenos fragmentos ( $3 \mathrm{~mm}$ x $3 \mathrm{~mm}$ x $3 \mathrm{~mm}$ ) foram retirados da parte cortical do ovário, transferidos para uma solução de $\mathrm{NaCl}$ 0,9\% em temperatura ambiente e divididos em 4 grupos: controle (sem exposição e fixado imediatamente), 10, 20 e $40 \%$. Os fragmentos de cada grupo foram expostos por 10 minutos ao etileno glicol nas concentrações de 10, 20 e $40 \%$, diluído em solução de $\mathrm{NaCl}$ a $0,9 \%$. Os fragmentos foram submetidos a exposição de forma gradual, da menor concentração para a maior, por período de um minuto em cada concentração. Em seguida, para retirada do crioprotetor, procedeu-se inversamente utilizando as mesmas concentrações e tempo. Após a exposição ao etileno glicol, os fragmentos foram fixados em Carnoy (Reagentes da marca registrada Synth) por $12 \mathrm{~h}$. As amostras foram desidratadas em etanol, clarificadas com xilol, embebidas em parafina e seccionadas a $5 \mu \mathrm{m}$. Os cortes foram corados com hematoxilina e eosina (HE) e examinados em microscópio óptico em aumento de 400X.
Os folículos pré-antrais foram classificados de acordo com o estágio de desenvolvimento em primordial (uma camada de células da granulosa de forma pavimentosa ou pavimentosa-cúbica ao redor do ovócito), primários (uma camada de células da granulosa de forma cúbica ao redor do ovócito) e pequenos secundários (duas ou mais camadas de células da granulosa de forma cúbica). As células da granulosa foram contadas e a morfometria ovocitária e folicular foram mensuradas, utilizando-se ocular com escala micrométrica (Wezel \& Rodgers, 1996; Kacinskis et al., 2005).

Os dados foram analisados por ANOVA e o teste de Tukey aplicado quando encontrado variação. Foram realizadas cinco repetições por tratamento (cada repetição correspondeu a um ovário). Os valores foram considerados significativos quando $\mathrm{P}<0,05$.

\section{RESULTADOS E DISCUSSÃO}

Foram analisados um total de 474 folículos inclusos em tecido ovariano bovino, entre folículos primordiais $(\mathrm{n}=287)$ e primários $(\mathrm{n}=187)$. Os pequenos folículos secundários não foram computados em função do reduzido número de estruturas encontradas. Os resultados quanto ao diâmetro dos folículos e dos ovócitos e quanto ao número de células da granulosa de folículos primordiais, encontramse na Tabela 1. Observou-se diferença significativa $(\mathrm{P}<0,05)$ entre o grupo $40 \%$ versus controle, $10 \%$ e $20 \%$ com relação ao diâmetro dos folículos e ovócitos. Com relação ao número de células da granulosa, ocorreu diferença significativa entre o grupo controle versus grupo $40 \%$. Os grupos controle, $10 \%$ e $20 \%$ foram iguais $(\mathrm{P}>0,05)$ entre si, assim como os grupos $10 \%, 20 \%$ e $40 \%$ também foram iguais $(\mathrm{P}>0,05)$.

$\mathrm{Na}$ Tabela 2, apresentam-se os resultados obtidos a partir das análises dos folículos primários. Não foi observada nenhuma diferença estatística entre os grupos estudados $(\mathrm{P}>0,05)$.

Tabela 1 - Média e desvio padrão do diâmetro folicular e ovocitário em micrômetros e número de células da granulosa de folículos primordiais dos grupos: controle, 10, 20 e 40\% de ovários obtidos em abatedouro de vacas Bos taurus indicus.

\begin{tabular}{ccccc}
\hline $\begin{array}{c}\text { Folículos } \\
\text { Primordiais }\end{array}$ & $\mathrm{n}$ & $\begin{array}{c}\text { Diâmetro do Folículo } \\
\text { (variação) }\end{array}$ & $\begin{array}{c}\text { Diâmetro do Ovócito } \\
\text { (variação) }\end{array}$ & $\begin{array}{c}\text { Células da Granulosa } \\
\text { (variação) }\end{array}$ \\
\hline Grupo Controle & 112 & $37,5 \pm 5,0(27,5-50)^{\mathrm{a}}$ & $25,7 \pm 4,1(15-35)^{\mathrm{a}}$ & $7,2 \pm 2,8(1-14)^{\mathrm{a}}$ \\
Grupo 10\% & 46 & $37,8 \pm 4,6(30-57,5)^{\mathrm{a}}$ & $25,8 \pm 4,3(17,5-42,5)^{\mathrm{a}}$ & $6,6 \pm 2,4(1-12)^{\mathrm{a}, \mathrm{b}}$ \\
Grupo 20\% & 53 & $37,4 \pm 3,8(30-47,5)^{\mathrm{a}}$ & $24,57 \pm 3,6(17,5-35)^{\mathrm{a}}$ & $6,6 \pm 1,7(2-10)^{\mathrm{a}, \mathrm{b}}$ \\
Grupo 40\% & 76 & $33,1 \pm 5,1(25-45)^{\mathrm{b}}$ & $22,19 \pm 3,8(15-32,5)^{\mathrm{b}}$ & $5,8 \pm 2,1(3-11)^{\mathrm{c}, \mathrm{b}}$ \\
\hline Total & 287 & - & - & - \\
\hline
\end{tabular}

${ }^{\mathrm{a}-\mathrm{c}}$ Diferentes sobrescritos na mesma coluna indicam diferença significativa $(\mathrm{P}<0,05)$. 
Tabela 2 - Média e desvio padrão do diâmetro folicular e ovocitário em micrômetros e número de células da granulosa de folículos primários dos grupos controle, 10, 20 e 40\% de ovários obtidos em abatedouro de vacas Bos taurus indicus.

\begin{tabular}{ccccc}
\hline Folículos Primários & $\mathrm{n}$ & $\begin{array}{c}\text { Diâmetro do Folículo } \\
\text { (variação) }\end{array}$ & $\begin{array}{c}\text { Diâmetro do Ovócito } \\
\text { (variação) }\end{array}$ & $\begin{array}{c}\text { Células da Granulosa } \\
\text { (variação) }\end{array}$ \\
\hline Grupo Controle & 35 & $47,5 \pm 9,4(35-70)$ & $27,1 \pm 4,6(17,5-40)$ & $14,5 \pm 5,4(7-29)$ \\
Grupo 10\% & 50 & $45,4 \pm 8,9(35-80)$ & $26,3 \pm 5,5(17,5-55)$ & $13,4 \pm 5,2(6-29)$ \\
Grupo 20\% & 59 & $44,1 \pm 7,3(32,5-67,5)$ & $25,8 \pm 4,5(17,5-40)$ & $12,2 \pm 4,5(6-30)$ \\
Grupo 40\% & 43 & $45,9 \pm 10,4(32,5-75)$ & $25,1 \pm 5,0(13-42,5)$ & $13,3 \pm 4,7(7-27)$ \\
\hline Total & 187 & - & - & - \\
\hline
\end{tabular}

É importante observar a propriedade dos crioprotetores de penetrar as membranas celulares. Esse efeito do crioprotetor deve-se à permeabilidade intra e extra celular. No presente estudo, foi utilizado o etileno glicol, o qual apresenta baixo peso molecular (massa molecular $=62,068) \mathrm{e}$, decorrente desta característica, possui maior permeabilidade do que outros agentes utilizados, como o dimetilsulfóxido, o propileno glicol e o glicerol (Newton et al., 1998).

Em relação ao efeito do etileno glicol no tecido ovariano, estudos indicam efeitos dependentes da espécie. Nesse sentido, Lucci et al. (2004) mostraram que o etileno glicol, em bovinos, é mais tóxico quando comparado a outros crioprotetores nessa espécie. Em roedores, Candy et al. (1997), não verificaram efeitos tóxicos para criopreservar tecido ovariano, porém alertaram para exposição por períodos prolongados poder ocasionar redução de viabilidade. Newton et al. (1996), em humanos, obtiveram resultados satisfatórios utilizando-se etileno glicol em protocolo de criopreservação.

Lucci et al. (2004) relataram que as fases de desenvolvimento folicular (primordiais, primários e pequenos secundários) não influenciaram, de maneira geral, a resistência dos folículos aos crioprotetores. Entretanto, Gandolfi et al. (2006), em experimento com criopreservação de fragmentos ovarianos de bovinos e humanos, verificaram maior sensibilidade de folículos primordiais, quando comparados aos primários e secundários, porém, essas diferenças não foram observadas em suínos.

O fato de os folículos primários não terem sofrido nenhum tipo de efeito do etileno glicol pode sugerir que o maior número de células da granulosa presente no folículo primário, comparado ao primordial, apresenta-se como uma barreira protetora aos efeitos da alta permeabilidade do etileno glicol no tecido ovariano bovino.

Estudos com folículos pré-antrais, inclusos em tecido ovariano bovino, submetidos a processos de criopreservação devem ser sistematicamente desenvolvidos com finalidade de identificar-se substâncias que ofereçam menores riscos de citotoxicidade durante o processo de criopreservação aos sistemas biológicos.

\section{CONCLUSÕES}

Os resultados obtidos sugerem que folículos primordiais bovinos são mais sensíveis à altas concentrações de etileno glicol do que primários com relação a alterações no número de células da granulosa e modificações morfométricas.

\section{AGRADECIMENTOS}

Agradecemos a FUNDECT pelo apoio financeiro.

\section{REFERÊNCIAS BIBLIOGRÁFICAS}

AGCA, Y.; LIU, J.; RUTLEDGE, J.J.; CRITSER, E.S.; CRITSER, J.K. Effect of osmotic stress on the developmental competence of germinal vesicle and metaphase II stage bovine cumulus oocyte complexes and its relevance to cryopreservation. Molecular Reproduction and Development, Hoboken, v.55, p.212-219, 2000.

AMORIM, C.A.; RODRIGUES, A.P.R.; RONDINA, D.; GONÇALVES, P.B.D.; FIGUEIREDO, J.R.; GIORGETTI, A. Cryopreservation of ovine primordial follicles using dimethylsulfoxide. Fertility and Sterility, New York, v.79, p.682-686, 2003.

AUBARD, Y.; POIROT, C.; PIVER, P.; GALINAT, S.; TEISSIER, M.P. Are there indications for ovarian tissue cryopreservation? Fertility and Sterility, New York, v.76, p.414-415, 2001.

CANDY, C.J.; WOOD, M.J.; WHITTINGHAM, D.G. Effect of cryoprotectants on the survival of follicles in frozen mouse ovaries. Journal of Reproduction and Fertility, Cambridge, v.110, p.11-19, 1997. 
CANDY, C.J.; WOOD, M.J.; WHITTINGHAM, D.G. Restoration of a normal reproductive lifespan after grafting o cryopreserved mouse ovaries. Human Reproduction, Oxford, v.15, p.1300-1304, 2000.

DEMIRCI, B.; LORNAGE, J.; SALLE, B.; POIRELA, M.P.; GUERINB, J.F.; FRANCKA, M. The cryopreservation of ovarian tissue: uses and indications in veterinary medicine. Theriogenology, New York, v.60, p.999-1010, 2003.

DONNEZ, J.; BASSIL, S. Indications for cryopreservation of ovarian tissue. Human Reproduction, Oxford, v.4, p.248-259, 1998.

FUKU, E.; LIU, J.; DOWNEY, B.R. In vitro viability and ultrastructural changes in bovine oocytes treated with a vitrification solution. Molecular Reproduction and Development, Hoboken, v.40, p.177-185, 1995.

GANDOLFI, F.; PAFFONI, A.; BRAMBILLA, E.P.; BONETTI, S.; BREVINI, T.A.L.; RAGNI, G. Efficiency of equilibrium cooling and vitrification procedures for the cryopreservation of ovarian tissue: comparative analysis between human and animal models. Fertility and Sterility, New York, v.85, p.1150-1156, 2006.

KACINSKIS, M.A.; LUCCI, C.M.; LUQUE, M.C.A.; BAO, S. Morphometric and ultrastructural characterization of Bos indicus preantral follicles. Animal Reproduction Science, Amsterdam, v.87, p.45-57, 2005.

LIMA, A.K.F.; SILVA, A.R.; SANTOS, R.R.; SALES, D.M.; EVANGELISTA, A.F; FIGUEIREDO, J.R.; SILVA, L.D.M. Cryopreservation of preantral ovarian follicles in situ from domestic cats (Felis catus) using different cryoprotective agents. Theriogenology, New York, v.66, p.1664-1666, 2006.

LUCCI, C.M.; KACINSKIS, M.; LOPES, L.H.R.; RUMPF, R.; BÁO, S.N. Effect of different cryoprotectants on the structural preservation of follicles in frozen zebu bovine (Bos indicus) ovarian tissue. Theriogenology, New York, v.61, p.1101-1114, 2004.

NEWTON, H.; AUBARD, Y.; RUTHERFORD, A.; SHARMA, V.; GOSDEN, R. Low temperature storage and grafting of human ovarian tissue. Human Reproduction, Oxford, v.11, p.1487-1491, 1996.
NEWTON, H.; FISHER, J.;ARNOLD, J.R.; PEGG, D.E.; FADDY, M.J.; GOSDEN, R.G. Permeation of human ovarian tissue with cryoprotective agents in preparation for cryopreservation. Human Reproduction, Oxford, v.13, p.376-380, 1998.

OKTAY, K. Ovarian tissue cryopreservation and transplantation: preliminary findings and implications for cancer patients. Human Reproduction, Oxford, v.7, p.526-534, 2001

OKTAY, K.; KARLIKAYA, G. Ovarian function after autologous transplantation of frozen, banked autologous ovarian tissue. New England Journal of Medicine, Waltham, v.342, p.1919, 2000.

PAYNTER, S.J.; COOPER, A.; FULLER, B.J.; SHAW, R.W. Cryopreservation of bovine ovarian tissue: structural normality of follicles after thawing and culture in vitro. Cryobiology, San Diego, v.38, p.301-308, 1999.

POSADA, M.N.; KOLP, L.; GARCÝA, J.E. Fertility options for female cancer patients: facts and fiction. Fertility and Sterility, New York, v.75, p.647-656, 2001

SCHALKOLFF, E.M.; OSKOWITZ, P.S.; POWERS, R.D. Ultrastructural observations of human and mouse oocytes treated with cryopreservatives. Biology of Reproduction, Madison, v.40, p.379-393, 1989.

SILVA, J.R.V.; LUCCI, C.M.; CARVALHO, F.C.A.; BÁO, S.N.; COSTA, S.H.F.; SANTOS, R.R.; FIGUEIREDO, J.R. Effect of coconut water and Braun-Collins solutions at different temperatures and incubation times on the morphology of goat preantral follicles preserved in vitro. Theriogenology, New York, v.54, p.809-822, 2000.

VINCENT, C.; PICKERING, S.J.; JOHNSON, M. The hardening effect of dimethylsulphoxide on the mouse zona pellucida requires the presence of an oocytes and is associated with a reduction in the number of cortical granules present. Journal of Reproduction and Fertility, Cambridge, v.89, p.253-259, 1990.

WEZEL, I. van; RODGERS, R.J. Morphological characterization of bovine primordial follicles and their environment in vivo. Biology of Reproduction, Madison, v.55, p.1003-1011, 1996. 